\title{
Peranan Penyuluh Pertanian Dalam Meningkatkan Kinerja Kelembagaan Kelompok Tani Padi Sawah Penerima Bantuan Rice Milling Unit (RMU) Di Kota Bandar Lampung
}

\section{The Role of Agricultural Extension in Improving the Institutional Performance of Rice Milling Unit (RMU) Farmer Groups in the City of Bandar Lampung}

\author{
Flora Defika $^{1 *}$, Irwan Effendi ${ }^{1}$, Kordiyana K. Rangga ${ }^{1}$ \\ 1) Jurusan Agribisnis, Fakultas Pertanian, Universitas Lampung. \\ *E-mail: bellas81mommy@gmail.com
}

\begin{abstract}
This study aims to analyze: 1) the level of the role of agricultural agents; 2) the level of institutional performance of farmer groups; 3$)$ the relationship between the level of the role of agricultural extension agents and the institutional performance of rice farmer groups in the use of RMU in Bandar Lampung City. This research was conducted in the city of Bandar Lampung with 56 farmer respondents. Methods of data collection using a survey method, with descriptive analysis and using a non-parametric rank spearman correlation statistical test to test the hypothesis. The results showed that the role of agricultural extension agents in improving the institutionalization of rice farmer groups receiving RMU assistance was in the medium category, the institutional level of farmer groups in the use of RMU was in the medium category, and the role of agricultural instructors had a significant relationship with the institutional performance of farmer groups.
\end{abstract}

Key words: role, extension agent, institutional, farmers.

Disubmit : 18 Agustus 2020; Diterima: 20 Oktober 2020; Disetujui: 26 April 2021

\section{PENDAHULUAN}

Pembangunan sektor pertanian khususnya subsektor tanaman pangan memiliki peran penting dalam pemenuhan kebutuhan pangan khususnya subsektor tanaman pangan komoditas padi. Padi adalah tanaman yang nantinya dalam proses pengolahan akan menghasilkan beras yang menjadi makanan pokok penduduk Indonesia. Peningkatan pemenuhan kebutuhan pangan penting dilakukan karena dilihat dari jumlah penduduk di Indonesia terus meningkat tiap tahunnya. Apabila jika kebutuhan pangan tidak tercukupi akan berdampak pada kondisi sosial ekonomi dan politik suatu bangsa.

Provinsi Lampung merupakan salah satu provinsi di Indonesia dengan jumlah penduduk yang terus mengalami pertumbuhan setiap tahunnya. Menurut data Badan Pusat Statistik (2018), tercatat bahwa jumlah penduduk Provinsi Lampung mengalami pertumbuhan sebesar 1,03 persen dari tahun 2016 hingga 2017. Bertambahnya jumlah penduduk ini mengakibatkan semakin tingginya kebutuhan beras dalam negeri. Munculnya ketidakseimbangan antara peningkatan permintaan beras dengan ketersediaan beras dalam negeri 
dapat memicu kebijakan impor beras. Hal inilah yang menyebabkan pemerintah terus melakukan upaya untuk menjaga kestabilan produksi padi terutama di provinsi sentra penghasil padi.

Produksi padi Lampung mengalami peningkatan sebesar 2 - 9 persen sejak tahun 2014-2018 (Badan Pusat Statistik, 2018). Provinsi Lampung berpotensi untuk lebih meningkatkan produksi padinya jika dilihat dari produksi yang terus meningkat dalam lima tahun terakhir dengan seluruh kabupaten dan kota di Provinsi Lampung turut menjadi penyumbang bagi peningkatan produksi tersebut. Menurut data Dinas TPH Provinsi Lampung tahun 2019, Kota Bandar Lampung memiliki produksi padi dan luas panen terendah di Provinsi Lampung yaitu sebesar 9.512 ton GKG dan 1.709 hektar, namun produktivitas padi yang dihasilkan oleh Kota Bandar Lampung merupakan yang tertinggi dibandingkan kabupaten/kota lainnya yaitu sebesar 5,57 ton/ha.

Semakin berkurangnya luas lahan pertanian terutama lahan sawah di Kota Bandar Lampung tidak memungkinkan peningkatan produksi melalui program ekstensifikasi lahan. Strategi yang cocok untuk daerah tersebut dalam upaya peningkatan produksi adalah melalui kegiatan intensifikasi yaitu dengan lebih meningkatkan produktivitas lahan, antara lain dengan memasukkan unsur teknologi di dalam budidayanya. Tingginya produktivitas padi sawah ini menunjukkan bahwa petani di Bandar Lampung telah memiliki kesadaran dan berhasil mengoptimalkan lahan yang mereka miliki untuk memperoleh hasil produksi padi yang maksimal di tengah keterbatasan luas lahan yang mereka miliki.

Teknologi pascapanen penggilingan padi sebagai basis agribisnis berperan dalam memajukan perberasan nasional mendukung swasembada dan ketahanan pangan nasional. Baharsjah, Kasryono, dan Pasandaran (2014) menambahkan bahwa kebijakan swasembada beras telah dan masih akan tetap dilakukan oleh pemerintah. Ponto et al. (2017) menunjukkan bahwa pada tahun 2015 pemerintah melalui Kementerian Pertanian telah mengeluarkan dana dari Anggaran Pembangunan Belanja Negara (APBN) sebesar Rp16.9 triliun untuk mencapai program swasembada. Salah satu upaya pemerintah yang telah dilakukan adalah mendorong pemanfaatan teknologi pascapanen dan pengolahan hasil pertanian untuk meningkatkan nilai tambah yaitu bantuan program penggilingan padi Rice Milling Unit (RMU) melalui kelembagaan kelompok tani.

Kota Bandar Lampung termasuk yang pertama mendapatkan bantuan RMU berdasarkan data dari Dinas TPH Provinsi Lampung. Jumlah bantuan RMU di Kota Bandar Lampung sama yang diterima oleh Kabupaten Lampung Selatan dan Lampung Barat yang memiliki produksi padi lebih tinggi. Pemerintah memandang bahwa penempatan RMU di Kota Bandar Lampung sangat strategis. Daerah perkotaan memberikan peluang pasar sangat terbuka karena dekat dengan target konsumen. Fasilitasi RMU kepada kelompok tani di perkotaan dengan luas kepemilikan lahan yang terbatas memberikan petani anggota peluang untuk meningkatkan pendapatannya dengan meningkatkan nilai tambah produk dari sebelumnya menjual dalam bentuk gabah kering panen (GKP) atau gabah kering giling (GKG) setelah menerima bantuan mereka dapat menjual produknya dalam bentuk beras.

Proses adopsi teknologi baru disuatu wilayah tidak lepas dari peranan dari penyuluh sebagai agen perubahan. Artinya tingkat keberhasilan kelembagaan kelompok tani dalam penerapan pemanfatan RMU diperlukan peranan penyuluh pertanian. Peran penyuluh tidak hanya sebagai fasilitator atau pendamping saja, akan tetapi peran penyuluh yang terpenting adalah harus mampu memberikan kontribusi kepada petani terkait permasalahan petani terkait usahatani yang dihadapi. Menurut Fiaz, Mehmood, dan Fahad (2016) peran penyuluh sangat penting untuk membantu mempromosikan teknologi inovatif sesuai dengan kebutuhan petani. Selain itu temuan Lusiana et al (2018) menyatakan bahwa penyuluh berperan dalam meningkatkan pendapatan usahatani petani. 
Kerjasama antara penyuluh pertanian dengan kelompok tani sangat diperlukan untuk menghasilkan petani yang baik dan berkualitas (Putra, 2016). Selain itu, pembinaan kelompok tani diharapkan dapat membantu menggali potensi, memecahkan permasalahan usahatani anggotanya secara lebih efektif dan memudahkan dalam mengakses informasi pasar, teknologi, permodalan dan sumber daya lainnya (Permentan, 2007). Menurut Najib dan Rahwita (2010) peran penyuluh yang perlu dilakukan adalah meningkatkan efektivitas sistem kerja kunjungan dari kegiatan penyuluhan guna menumbuhkan peran petani, pembangunan pertanian, dengan melakukan pembinaan terhadap kelompok-kelompok tani yang telah terbentuk agar nantinya kelompok tani mampu berkembang menjadi kekuatan ekonomi yang memadai dan selanjutnya mampu menopang kesejahteraan anggotanya.

Pentingnya peranan penyuluh tentunya akan memberikan manfaat bagi kinerja kelembagaan kelompoktani. Namun sejauh ini peran penyuluh pertanian dirasa kurang dinamis. Selain itu adanya UU Nomor 16 tahun 2006 yang mengamanatkan satu desa satu penyuluh tidak menutup kemungkinan intensitas penyuluhannya menjadi berkurang karena jumlah penyuluh yang ada di lapangan belum mmnuhi kriteria tersebut. Hal ini pasti akan mempengaruhi persepsi petani terhadap kinerja penyuluh. Hal ini juga didukung dari hasil penelitian Nashruddin (2016) menyatakan bahwa penilaian petani terhadap kinerja penyuluh dinilai kurang memuaskan, hal ini dikarenakan rendahnya reponsivitas kemampuan penyuluh untuk mengatasi permasalahan yang terjadi di petani dan penyuluh dianggap kurang intensif kunjungan ke petani. Dipertegas juga oleh temuan Wijayanti et al (2015) yang menyatakan bahwa petani belum puas terhadap kinerja penyuluh.

Berdasarkan uraian di atas, maka tujuan dari penelitian ini adalah untuk mengetahui: 1) tingkat peranan penyuluh pertanian; 2) tingkat kinerja kelembagaan kelompok tani; 3) hubungan antara tingkat peranan penyuluh pertanian dengan kinerja kelembagaan kelompok tani padi sawah dalam pemanfaatan RMU di Kota Bandar Lampung.

\section{METODE PENELITIAN}

Metode penelitian yang digunakan adalah metode survei. Penelitian ini dilakukan di Kota Bandar Lampung. Lokasi penelitian dipilih secara sengaja (purposive) dengan pertimbangan Kota Bandar Lampung memperoleh bantuan RMU sebanyak lima unit di lima kelompok taninya. Selain itu Kota Bandar Lampung sebagian besar masyarakatnya terdiri dari kalangan pendapatan menengah ke atas yang cenderung mengkonsumsi beras kualitas yang tinggi, sehingga teknologi RMU tepat diterapkan oleh petani dengan kondisi masyarakat di Kota Bandar Lampung.

Populasi pada penelitian ini adalah petani yang tergabung pada kelompok tani penerima bantuan RMU. Berdasarkan data Dinas Tanaman Pangan dan Hortikultura (2019) diketahui bahwa jumlah kelompok tani yang menerima RMU di Kota Bandar Lampung adalah 5 kelompok tani yang terdiri 3 poktan di Kecamatan Rajabasa, 1 poktan di Kecamatan Tanjung Senang, dan 1 poktan di Sukarame dengan total anggota poktan yaitu 129 petani. Sampel diambil secara acak (proportional random sampling) sehingga diperoleh jumlah sampel sebanyak 56 responden.

Data yang dikumpulkan dalam penelitian ini adalah data primer dan data sekunder. Data primer diperoleh melalui metode survei, yaitu mewawancarai secara langsung petani padi dengan menggunakan daftar pertanyaan (kuesioner) yang telah disediakan sebagai alat bantu pengumpulan data. Data sekunder diperoleh dari studi literatur, laporan-laporan, publikasi, dan pustaka lainnya yang berhubungan dengan penelitian ini, serta lembaga/instansi yang terkait. Pengambilan data dilakukan pada bulan Januari - Maret 2020. Analisis data yang digunakan dalam penelitian ini metode deskriptif kualitatif dengan menggunakan Skala Interval, Skala Likert dan Rank Spearman. 


\section{HASIL DAN PEMBAHASAN}

\section{Tingkat Peranan Penyuluh Pertanian Lapang}

Peranan penyuluh pada penelitian ini dilihat dari bentuk realisasi dari peran yang diemban oleh seorang penyuluh itu sendiri yaitu antara lain melakukan edukasi, diseminasi, fasilitasi, konsultasi, supervisi, pemantauan, dan evaluasi. Sebaran penilaian responden terhadap peranan penyuluh dalam membimbing petani dalam pemanfaatan RMU di Kota Bandar Lampung dapat dilihat pada Tabel 1.

Tabel 1. Sebaran penilaian responden terhadap peranan penyuluh di Kota Bandar Lampung

\begin{tabular}{cclrr}
\hline No. & Peranan Penyuluh & \multicolumn{1}{c}{ Kategori } & Jumlah (Orang) & \multicolumn{1}{c}{$\%$} \\
\hline 1 & $34,00-38,75$ & Rendah & 4 & 7,14 \\
2 & $38,76-43,51$ & Sedang & 27 & 48,21 \\
3 & $43,52-48,27$ & Tinggi & 22 & 39,29 \\
4 & $48,28-53,00$ & Sangat tinggi & 3 & 5,36 \\
\hline Total & & & 56 & 100,00 \\
\hline
\end{tabular}

Berdasarkan Tabel 1 dapat dilihat bahwa sebagian besar responden menilai peranan penyuluh dalam membimbing petani untuk memanfaatkan RMU termasuk dalam klasifikasi sedang. Penyuluh di Kota Bandar Lampung dinilai telah melaksanakan perannya sebaik mungkin dalam melaksanakan tugasnya sebagai pendamping petani binaannya, sehingga petani merasakan peranan penyuluh sebagai edukasi, desiminasi, fasilitasi, konsultasi, supervisi, pemantau, dan sebagai evaluasi dengan cukup baik. Peran penyuluh dalam penelitian termasuk dalam klasifikasi sedang dikarenakan masih rendahnya peran penyuluh untuk memperoleh informasi yang dibutuhkan penyuluh yang digunakan untuk melakukan pembinaan. Hasil ini sejalan dengan penelitian Damanik (2014) yang menunjukkan bahwa penyuluh seringkali mengalami kesulitan mengakses informasi-informasi yang dibutuhkan untuk menyuluh.

Menurut van den Ban dan Hawkins (1999) kemampuan agen penyuluhan untuk mempengaruhi petani dapat ditingkatkan seiring dengan pembangunan dibidang teknologi komunikasi dan informasi, serta penggunaan ilmu-ilmu sosial dalam penyuluhan. Hal ini berarti kapasitas penyuluh di Kota Bandar Lampung masih dapat ditingkatkan lagi. Peningkatan kapasitas penyuluh dapat diperoleh dari pelatihan-pelatihan kepenyuluhan maupun dengan cara memperluas wawasan secara mandiri dengan lebih memperbarui informasi-informasi tentang teknis penyuluhan dan informasi terkait teknologi RMU terbaru. Selain itu, berdasarkan hasil penelitian Humaedah, et al (2016) unbtuk meningkatkan kapasitas penyuluh dapat dilakukan dengan meningkatkan aksesibilitas terhadap sumber informasi, pengelolaan informasi serta dimensi pemilihan metode penyuluhan. Rekomendasi perbaikannya adalah dengan pendekatan struktural melalui peningkatan sinergitas antara kelembagaan terkait dalam peningkatan kapasitas penyuluh dan sumber informasi.

\section{Kinerja Kelembagaan Kelompok Tani}

Kelompok tani dalam penelitian ini berperan penting dalam pemanfaatan RMU oleh petani setempat. Kinerja kelembagaan kelompok tani dalam penelitian ini dilihat dari Kerjasama anggota dan pengurus, peranan ketua kelompok tani, kinerja pengurus, pemenuhan fasilitas pendukung RMU, dan pemeliharaan fasilitas RMU. Sebaran penilaian responden terhadap kinerja kelembagaan kelompok tani dapat dilihat pada Tabel 2. 
Tabel 2. Kinerja Kelembagaan Kelompok Tani

\begin{tabular}{cclcc}
\hline No. & $\begin{array}{c}\text { Kinerja kelembagaan } \\
\text { kelompok tani }\end{array}$ & \multicolumn{1}{c}{ Kategori } & Jumlah (Orang) & $\%$ \\
\hline 1 & $7,00-9,75$ & Rendah & 16 & 28,57 \\
2 & $9,76-12,51$ & Sedang & 23 & 41,07 \\
3 & $12,52-15,27$ & Tinggi & 13 & 23,21 \\
4 & $15,28-18,00$ & Sangat tinggi & 4 & 7,14 \\
\hline & Total & & 56 & 100,00 \\
\hline
\end{tabular}

Tabel 2 menunjukkan bahwa sebagian besar responden menilai kinerja kelembagaan kelompok tani dalam pemanfaatan RMU masuk dalam kategori rendah yaitu sebanyak 23 orang atau 41,07 persen. Hal ini berarti kelompok tani belum cukup optimal kinerjanya dalam pemanfaatan RMU. Hal tersebut masih perlu menjadi fokus perhatian dari penyuluh agar dapat lebih optimal dalam melakukan pendampingan sehingga kelompok tani dan anggotanya dapat lebih aktif memanfaatkan RMU.

Keberhasilan suatu kelompok tani dalam mengaktifkan kegiatan kelompok tani tidak terlepas dari peran ketua kelompok. Peran ketua kelompok yang aktif akan memberikan pengaruh positif terhadap kinerja pengurus kelompok tani. Hal tersebut akan membuat anggota kelompok tani ikut berperan aktif dalam kelompok dan khususnya dalam pemanfaatan RMU yang dikelola kelompok tani, sehingga dalam hal tersebut diperlukan kemampuan yang baik bagi ketua kelompok untuk memotivasi anggota kelompok tani agar mau ikut berpartisipasi dalam kegiatan kelompok tani. Ngaruko dan Lwezaula (2013) yang menyatakan bahwa ketidakpuasan akan menurunkan partisipasi petani dalam suatu kelompok. Ketidakpuasan berkaitan dengan perilaku pemimpin kelompok yang belum bisa melayani tanpa pamrih untuk kepentingan anggotanya dan membina kelompok secara demokratis. Menurut Rangga, et al (2019) menyatakan bahwa kepemimpinan ketua kelompok tani memiliki peran yang penting dalam pencapaian tujuan kelompok.

Rendahnya kinerja kelompok tani dalam pemanfaatan RMU tidak sejalan dengan fasilitas pendukung RMU yang telah tercukupi. Beberapa fasilitas pendukung tersebut antara lain tersedianya kendaraan pengangkut gabah ke penggilingan, adanya lantai jemur atau dryer sehingga mempercepat proses pengeringan gabah petani, adanya gudang simpan yang dapat digunakan untuk menyimpan gabah sebelum digiling atau menyimpan beras yang sudah digiling sebelum dijual.

Manajemen pengelolaan RMU oleh pengurus kelompok selama ini sudah berjalan dengan baik. Ketua kelompok dan pengurus berhasil mengembangkan usaha RMU kelompok sehingga kelompok tani juga menampung gabah dari luar anggota bahkan dari luar kota. Anggota kelompok juga tidak perlu merasa khawatir memikirkan pemasaran produknya karena biasanya kelompok tani sudah bekerjasama dengan instansi pemerintah contohnya dinas pertanian serta pemerintah kota lainnya untuk memasok kebutuhan beras pegawainya.

Anggota kelompok yang akan menggiling padi menggunakan RMU yang dikelola kelompok tani akan dikenakan tarif yang disepakati bersama berupa bawon beras dengan perbandingan 10:1 atau setiap sepuluh kilogram beras yang dihasilkan maka akan dibayar dengan satu kilogram beras untuk kelompok tani atau jika diuangkan maka tarif penggilingan berkisar Rp500,00 sampai dengan Rp600,00 per kilogram berasnya. Tarif tersebut dimanfaatkan sebagai uang kas kelompok serta untuk perawatan RMU. Pemasukan kelompok tidak hanya dari tarif penggilingan tetapi juga dari penjualan bekatul dan merang sisa dari penggilingan yang disepakati bersama menjadi hak kelompok.

Adanya uang kas kelompok memungkinkan kelompok untuk leluasa mengembangkan usahanya, melakukan pemeliharaan mesin RMU yang digunakan untuk penggilingan agar dapat berfungsi dengan baik, meningkatkan kesejahterakan anggotanya dengan pemberian Sisa Hasil Usaha (SHU) serta menyediakan modal awal untuk budidaya padi anggota kelompoknya. Sejalan dengan penelitian Hellin, Lundy dan Meijer (2007) yang menyatakan bahwa kelompok tani memberikan manfaat dalam kemudahan mengakses pinjaman 
bagi para petani dan dapat membantu para anggotanya dalam meningkatkan penyebaran informasi. Selain itu, dengan makin baiknya kelompok dalam mengelola modal dan aset yang dimiliki membuat anggota kelompoknya semakin percaya dan dengan mudah mengikuti setiap kebijakan yang ditetapkan oleh kelompok. Sebaliknya pada kelembagaan kelompok tani penerima RMU yang tertutup dalam pengelolaan modal dan asetnya membuat petani anggotanya kurang menaruh kepercayaan terhadap kelompok tani untuk mengolah hasil panennya.

\section{Hubungan peranan penyuluh pertanian dengan kinerja kelembagaan kelompok tani}

Hubungan antara peranan PPL dengan kinerja kelembagaan kelompok tani dianalisis dengan menggunakan statistika non parametrik uji korelasi Rank Spearman dengan bantuan SPSS 25 . Sugiyono (2015) menjelaskan bahwa korelasi Rank Spearman, sumber data untuk kedua variabel yang akan dikonversikan dapat berasal dari sumber yang tidak sama, jenis data yang dikorelasikan adalah data ordinal, serta data dari kedua variabel tidak harus membentuk distribusi normal. Jadi korelasi Rank Spearman adalah bekerja dengan data ordinal atau berjenjang/ranking, dan bebas distribusi. Hasil pengujian statistik peranan penyuluh (PPL) dengan kinerja kelembagaan kelompok tani petani padi sawah dapat dilihat pada Tabel 3.

Tabel 3. Hasil analisis peranan penyuluh dengan kinerja kelembagaan kelompok tani padi sawah

\begin{tabular}{cccc}
$\begin{array}{c}\text { Variabel } \\
\text { X1 }\end{array}$ & $\begin{array}{c}\text { Variabel } \\
\text { X2 }\end{array}$ & $\begin{array}{c}\text { Koefisien } \\
\text { korelasi }\left(\mathbf{r}_{\mathbf{s}}\right)\end{array}$ & $\begin{array}{c}\text { sig. } \\
(\mathbf{1 - t a i l e d})\end{array}$ \\
\hline Peranan PPL & Kelembagaan Kelompok Tani & $0,329^{*}$ & 0,013
\end{tabular}

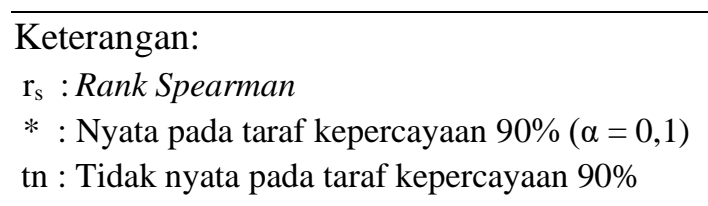

Berdasarkan hasil pengujian hipotesis hubungan antara peranan PPL (edukasi, diseminasi, fasilitasi, konsultasi, supervisi, pemantauan, dan evaluasi) dengan kinerja kelembagaan kelompok tani petani padi sawah di Bandar Lampung dengan menggunakan uji statistik nonparametrik korelasi Rank Spearman diperoleh hasil $\mathrm{p}$ sebesar 0,013 dan $\alpha$ 0,1, sejalan dengan kaidah keputusan jika $\mathrm{p} 0,013<\alpha 0,1$ dapat disimpulkan bahwa peranan penyuluh berhubungan nyata dengan arah positif terhadap kinerja kelembagaan kelompok tani petani padi sawah di Bandar Lampung dengan taraf kepercayaan 90 persen.

Hasil penelitian ini sesuai dengan penelitian yang dilakukan oleh Faqih (2014); Suria et al. (2016) bahwa peran penyuluh (PPL) berhubungan dengan perkembangan kinerja kelembagaan kelompok tani. Winarni dkk (2015) menjelaskan bahwa peran penyuluh sebagai fasilitator terdapat hubungan dengan pengembangan kelompok tani yaitu meningkatkan pengetahuan petani, termasuk di dalamnya gencar mencari pelatihan, seminar atau kegiatan lain yang dilaksanakan oleh instansi terkait atau pihak lain untuk meningkatkan kelembagaan kelompok tani.

Penelitian ini mengungkapkan adanya hubungan yang searah antara peranan penyuluh PPL di Bandar Lampung dengan kinerja kelembagaan kelompok tani. Semakin tinggi peranan penyuluh maka semakin tinggi pula kinerja kelembagaan kelompok tani dalam mengimplementasikan pemanfaatan RMU. Peranan penyuluh dirasa memang dibutuhkan terutama sebagai fasilitator kelompok tani dengan pihak pemerintah karena melalui penyuluh para petani melalui kelompoknya dapat mengajukan permintaan perbaikan dan penambahan alat atau saran pendukung RMU. Selain itu semakin rutin penyuluh di Kota Bandar Lampung melakukan kunjungan semakin menjadikan kelompok tani merasa termotivasi untuk lebih 
produktif dalam kegiatan dan usaha taninya. Ini didukung oleh penelitian Qayyimah, Sadono, dan Dwi (2020), peran penyuluh sebagai fasilitator, mitra pemasaran, penganalisis lingkungan, pendamping petani, dan motivator berhubungan sangat nyata dengan tingkat keberdayaan petani. Tingkat keberdayaan dalam hal ini adalah kinerja petani yang merupakan anggota dari kelompok tani. Ruhimat (2017) menambahkan bahwa peran penyuluh berpengaruh terhadap peningkatan kapasitas kelembagaan kelompok tani dalam pengembangan usahatani.

\section{KESIMPULAN}

Berdasarkan hasil penelitian tentang hubungan peran penyuluh pertanian dengan kinerja kelembagaan kelompok tani pada pemanfaatan program RMU di Kota Bandar Lampung, maka dapat disimpulkan bahwa : 1) tingkat peranan penyuluh pertanian di Kota Bandar Lampung terkait kegiatan revitalisasi RMU secara keseluruhan termasuk dalam kategori sedang, terlihat dari sebagian besar peranan penyuluh dalam diseminasi, konsultasi, supervisi, pemantauan, dan evaluasi termasuk dalam kategori sedang. Hal ini menunjukkan masih kurangnya kapasitas penyuluh untuk melakukan peranannya terkait program pengembangan RMU. Penelitian ini juga menunjukkan bahwa peranan penyuluh sebagai edukator dan fasilitator dalam kegiatan ini tergolong tinggi; 2) tingkat kinerja kelembagaan kelompok tani di Kota Bandar Lampung terkait program RMU termasuk dalam kategori sedang. Hal ini dikarenakan masih kurangnya kapasitas kepemimpinan sebagian dari ketua kelompok tani dalam mengkoodinir kebutuhan anggotanya dan kurangnya kerjasama antara pengurus kelompok dengan anggotanya; 3) terdapat hubungan peranan penyuluh pertanian dengan kinerja kelembagaan kelompok tani di Kota Bandar Lampung. Peranan penyuluh dalam edukasi, diseminasi, fasilitasi, konsultasi, supervisi, pemantauan, dan evaluasi dalam penelitian ini bertujuan untuk meningkatkan kinerja kelembagaan kelompok tani.

\section{DAFTAR PUSTAKA}

Abbas, A., \& Suhaeti, R. N. (2016). Pemanfaatan Teknologi Pascapanen untuk Pengembangan Agroindustri Perdesaan di Indonesia. Forum Penelitian Agro Ekonomi, 34(1), 21. https://doi.org/10.21082/fae.v34n1.2016.21-34

Adong A, Mwaura F, O. G. (2013). What factor determine membership to farmer groups in Uganda? Evidence from the Uganda census of agriculture 2008/9. Journal of Sustainable Development, 6(4), 37 55.

Ambarsari I, A Choliq, dan S. B. (2007). Potensi Pengembangan Agroindustri Jambu Biji Merah di Kabupaten Banjar Negara (Studi Kasus Desa Kaliwunggu Kecamatan Mandiraja). Jurnal Litbang Pertanian Provinsi Jawa Tengah.

Badan Ketahanan Pangan Kementerian Pertanian. (2019). Direktori Perkembangan Konsumsi Pangan. Jakarta (ID).

Badan Pusat Statistik. (2018). Survei Sosial Ekonomi Nasional (Susenas) Tahun 2018. Jakarta.

Baharsjah S, F, K., \& E, P. (2014). Reposisi politik pertanian meretas arah baru pembangunan pertanian. Jakarta (ID): Yayasan Pertanian Mandiri.

Damanik, J. . (2014). Analisis Faktor-faktor yang Mempengaruhi Pendapatan Petani Padi di Kecamatan Masaran, Kabupaten Sragen. Economics Development Analysis Journal.

Faqih, A. (2014). Peranan Penyuluh Pertanian Lapangan (PPL) dalam kegiatan Pemberdayaan Kelompok terhadap Kinerja kelompok Tani. Jurnal Agrijati, 26(1), 201-441. 
Fiaz, S., Noor, M. A., \& Aldosri, F. O. (2018). Achieving food security in the Kingdom of Saudi Arabia through innovation: Potential role of agricultural extension. Journal of the Saudi Society of Agricultural Sciences, 17(4), 365-375. https://doi.org/10.1016/j.jssas.2016.09.001

Hellin, J., Lundy, M., \& Meijer, M. (2007). Farmer Organization, Collective Action and Market Access in Meso-America. Research Workshop on Collective Action And Market Access For Smallholders.

Hernanda, T. A. P. (2015). Kinerja Penyuluh Pertanian Di Kabupaten Ogan Komering Ulu (Oku) Selatan Provinsi Sumatera Selatan. Institut Pertanian Bogor.

Humaedah, U., Astrina, Y., Enti, S., L. (2016). Model Peningkatan Kapasitas Penyuluh Dalam Pemanfaatan Informasi Iklim Di Kabupaten Indramayu Dengan Pendekatan Analisis Keberlanjutan. Informatika Pertanian, 25(1), 131-144.

Lusiana, Laapo, A., \& Howara, D. (2018). Peran Penyuluh Pertanian Dalam Meningkatkan Pendapatan Usahatani Padi Sawah Di Desa Oloboju Kecamatan Sigi Biromaru Kabupaten Sigi. Jurnal Agrotekbis, $6(1), 40-47$.

Mardikanto, T. (2009). Komunikasi Pembangunan. Surakarta: UNS Press.

Munte, G. . (2017). Pengaruh Karakteristik Sosial Ekonomi Konsumen terhadap Preferensi Konsumen Beras. Journal On Social Economic Of Agriculture And Agribusiness, 6(1).

Najib, M. Rahwita, H. (2010). Peran Penyuluhan Petani Dalam Pengembangan Kelompok Tani Di Desa Bukit Raya Kecamatan Tenggarong.

Ngaruko, D., \& Lwezaula, D. (2013). Determinants of Farmer's Group Membership Satisfaction in Mbozi Distict, Tanzania: Exploring Farmers' Options. International Journal of Economy, Management and Social Science, 2(11), 919-923.

Olila DO. (2014). Economic Evaluation of Factors Affecting Farmers Participation in Development Groups: A Case of Trans-Nzoia Country, Kenya. Journal of Agricultural Economics, Extension and Rural Development, 2(6), 74-81.

Ponto, J., Benu, N. M., \& Kumaat, R. M. (2017). Upsus Pajale Dalam Menunjang Program Swasembada Pangan Di Kabupaten Bolaang Mongondow Jeremy Ponto This study aims to determine the trend of agricultural production in supporting food self-sufficiency program "PAJALE " in Bolaang Mongondow District. Thi. 13, 253-260.

Putra, S. (2016). Peran Penyuluh Pertanian Dalam Pengembangan Kelompok Tani Padi Sawah Di Desa Rambah Baru Kecamatan Rambah Samo Kabupaten Rokan Hulu.

Qayyimah, Sadono, N., \& Dwi. (2020). Peran Penyuluh dalam Memberdayakan Petani Padi Sawah di Desa Kampili, Kecamatan Pallangga, Kabupaten Gowa. Institut Pertanian Bogor.

Rangga, K. ., Irwan, E., Indah, L., \& Doni, P. (2019). Hubungan Kepemimpinan Ketua Kelompok dengan Keefektifan Kelompok Tani Padi Sawah di Kecamatan Sukoharjo Kabupaten Pringsewu. Jurnal Pengkajian Dan Pengembangan Teknologi Pertanian, 22(2), 145-155.

Robbins, S. P., \& Judge. (2007). Perilaku Organisasi. Jakarta: Salemba Empat.

Ruhimat, I., R. (2017). Peningkatan Kapasitas Kelembagaan Kelompok Tani Dalam Pengembangan Usahatani Agroforestry: Studi Kasus Di Desa Cukangkawung, Kecamatan Sodonghilir, Kabupaten 
Tasikmalaya, Provinsi Jawa Barat. Jurnal Penelitian Sosial Dan Ekonomi Kehutanan, 14(1), 1-17.

Santi, Nikmatullah, D., \& Prayitno, R. T. (2016). Tingkat Kinerja Penyuluh Pertanian Tanaman Pangan Di Bp3k Kecamatan Gadingrejo Kabupaten Pringsewu. Jiia, 4(3), 277-284.

Sugiyono. (2015). Metode Penelitian Pendidikan. Bandung: Alfabeta.

Suria, P., \& Defidelwina, R. (2016). Peran Penyuluh Pertanian Dalam Pengembangan Kelompok Tani Padi Sawah Di Desa Rambah Baru Kecamatan Rambah Samo Kabupaten Rokan Hulu. Universitas Pasir Pengaraian Rokan Hulu.

Tahlim Sudaryanto. (2013). Membangun Daya Tahan Pertanian Dan Pangan Melalui. (19), 15-26.

Van den Ban AW, H. H. (1999). Penyuluhan Pertanian (Edisi terjemahan oleh A. Dwina Herdiasti). Yogyakarta: Kanisius.

Wijayanti, N., Paranoan, D. B., \& Kalalinggi, R. (2015). Analisis Tingkat Kepuasan Petani Terhadap Kinerja Penyuluh Pertanian Lapangan ( Ppl ) Di Kabupaten Kutai Timur. eJournal Administrative Reform, 3(2), 263-275.

Winarni, I. (2015). Hubungan Pengawasan Dan Efektivitas Kerja Pertanian Pada Badan Penyuluhan. Kabupaten Kutai Timur. Samarinda. Ejournal Administrative Reform, 1(1), 89-98. 